\title{
Dynamic Constitutive Equation of Resistance Spot Weld Materials of TRIP780 Steel
}

\author{
Xiaomin Li ${ }^{1, *}$, Jianrong Zhang ${ }^{2}$ and Chao Liu $^{3}$ \\ ${ }^{1}$ Zhejiang Industry Polytechnic College, Shaoxing, 312000, Zhejiang, China \\ 2 Tongji University, Shanghai, 200092, China \\ 3 Sun Moon University, Chung Nam, 31460, Republic of Korea
}

Received 27 May 2020; Accepted 4 August 2020

\begin{abstract}
In studies on dynamic mechanical behaviour of metallic materials, obtaining the constitutive equation is crucial to analyze numerical values of dynamic mechanical behaviour of the material. To determine the dynamic constitutive equation of resistance spot weld (RSW) materials of TRIP780 steel, this study analyzed the relationship between micro-hardness and yield strength of the RSW material. Furthermore, a microscopic profile of the RSW material was observed through a metallographic test and the metallographic structure of the material was analyzed. The hardness distribution of the RSW material of TRIP780 steel was investigated by micro-hardness test. The conversion relation between hardness and yield strength of the material was analyzed and applied to obtain the constitutive equation of the RSW material. Design of the split Hopkinson pressure bar (SHPB) experimental apparatus was optimized and the validity of the proposed constitutive equation was verified by an experiment. Results show that the micro-hardness of the RSW material is high when the local martensite content in the welding spot is high. The dynamic constitutive equation of the RSW materials of TRIP780 steel was constructed. The SHPB experimental design was optimized. The reflection and transmission of medium wave of specimens are enhanced, thereby resulting in effective experimental results. The dynamic compressive behaviour of the RSW materials of TRIP780 steel has a strain rate dependence. Research conclusions can provide important references in studying the dynamic constitutive equation and mechanical responses of the RSW materials of TRIP780 steel.
\end{abstract}

Keywords: Resistance spot weld, Micro-hardness, Dynamic constitution, Strain rate dependence

\section{Introduction}

At present, the steel and automobile industries pay close attention to studies and applications of transformationinduced plasticity (TRIP) steel [1]. In automobile manufacturing, TRIP steel plates are used as body materials of vehicles and are connected through abundant welding spots. In general, a vehicle has 3000-5000 welding spots that form numerous resistance spot weld (RSW) lap joints with connected steel plates. When a car body suffers high-speed impact, strength and stability of the lap joints influence the security of the car body. Failure mechanism under impact loading is extremely important in the safe design of the car body and in understanding the mechanical behavior of RSW materials.

The microstructure of TRIP steel under room temperature mainly consists of ferrite, bainite, and retained austenite. This type of steel has a TRIP effect [2] through induced transformation from retained austenite to martensite by reshaping, accompanied with improvement of plasticity. Different from other high-strength steel plates, the TRIP steel plate is equipped with not only high strength but also excellent ductility. It is a type of high-strength steel plate with good comprehensive mechanical performances. At present, studies on TRIP steel mainly focus on the TRIP behavior of retained austenite [3-5] and influences of composition and structure on the TRIP steel performance within static or quasistatic ranges from the perspective of metallurgy and rolling

\footnotetext{
*E-mail address: 475559989@qq.com

ISSN: 1791-2377 @ 2020 School of Science, IHU. All rights reserved.

doi:10.25103/iestr.134.08
}

technology [6-7]. Studies have also been conducted on TRIP steel material model represented by stress-strain relations [8]. Although many studies and simulations on the mechanical behaviors of TRIP steel materials have been published, rare studies have been conducted on the mechanical features of RSW materials of TRIP steel for the use of vehicles.

On this basis, TRIP780 steel produced by Baosteel was selected as the study material. Relevant experiments and analyses of the RSW materials of TRIP780 steel were conducted, and a corresponding dynamic constitutive equation was proposed to describe the mechanical behaviors of the materials under high strain rate.

\section{State of the art}

Many experts have conducted substantial studies on TRIP780 steel materials. For instance, Renyong Huang[9] performed a torsion rebound test on TRIP 780 steel, but did not study the dynamic mechanical responses. Xianhong Han[10] tested the mechanical properties of TRIP 780 steel in the quenching and distribution process, but did not investigate the constitutive behaviors of the material. Xianhong Han[11] examined the influences of cooling speed on the mechanical properties of typical hot stamping shaping of TRIP780 steel. Chi Zhou [12] investigated the influences of strain path changes on the shaping properties of TRIP780 and believed that martensite phase transformation had positive effects on these shaping properties. Jie Zhu [13] conducted a numerical prediction of the shaping limit curve of TRIP 780 steel plates, but did not include the constitutive equation of the material. Haiyan $\mathrm{Yu}[14]$ proposed a hybrid isotropic movement hardening 
model of TRIP steel and simulated the TRIP effect. Kai Chen[15] analyzed the influences of welding parameters on the structural evolution of joints in the welding process of TRIP780 steel but did not explore the mechanical behaviors of the material under high strain rate. Matthieu Dunand [16] performed quasi-static and dynamic tensile experiments of TRIP780 steel plates and found that the predicted forcedisplacement curve agreed well with the force-displacement curve measured in the experiment. C. Mauduit [17] discussed the loading responses of TRIP780 steel fatigue samples under cyclic bending. Sang-Gyu Choi [18] predicted welding quality by selecting welding time and welding current as important parameters. Podany Pavel [19] tested the mechanical properties of welding joint through a mini-tensile experiment and conventional hardness measurement method. Petra Vanova [20] discussed influences of hydrogen content on the mechanical properties and fracture characteristics of TRIP780 steel. Volkan Onar [21] implemented a tensile peeling test of welding samples and analyzed the influences of welding time on tensile peeling performance. Iman Hajiannia [22] determined the best welding parameters by studying the micro-structure of the RSW joint of TRIP steel. Amir Mostafapour [23] investigated the influences of friction stir spot-welding parameters on the size of the fine zone, which was formed by thermal strain in the welding process of TRIP steel. Gladys Perez Medina [24] found transformation from austenite to martensite in the stirring zone of the friction stir welding process, resulting in loss of mechanical properties of the joint. Ruijun Xie [25] studied the mechanical properties and micro-structure of the RSW material of the TRIP steel and disclosed the relationship between nugget structure and mechanical properties, but did not investigate the mechanical behaviors under high strain rate.

The research results mainly focus on the mechanical behaviors of base material (BM) of TRIP780 steel, but rare studies have been conducted on the mechanical behavior of RSW materials of this steel. With references to the dynamic constitutive equation of TRIP780 steel, Roth [26] conducted Vickers hardness experiments simultaneously to RSW materials. According to a hypothesis proposed by Nielsen [27], a linear correlation exists between micro-hardness and yield stress. Then, the hardness of RSW materials can be attributed to that of BM, thereby enabling us to obtain the dynamic constitutive equation of these materials. A dynamic uniaxial compressive test of spot-welding material specimens was conducted on SHPB, obtaining stress-strain curves under different strain rates. A numerical simulation of the dynamic constitutive equation of the RSW material of TRIP780 was performed and findings were compared with the experimental results.

The rest of the paper is organized as follows. Section $3 \mathrm{p}$ repared the specimens of the RSW material, observed the micro-structure and tested the micro-hardness of the RSW material, and designed the dynamic compression test of the specimens. Section 4 analyzed the relationship between micro-hardness and yield strength of the RSW material, constructed the dynamic constitutive equation of the RSW material, and simulated the results of the dynamic compression of the specimens. Section 5 summarized the study.

\section{Methodology}

\subsection{Preparation of specimens}

In this study, TRIP780 steel plates were chosen to prepare specimens. The steel plate was $1.400 \mathrm{~mm}$ thick and two pieces of the same steel plates were connected through lap welding, which was then cut into the original spot-welding samples. Diameter of the welding spot was $5 \mathrm{~mm}$. Resistance spot-weld machine applied in this experiment is shown in Fig. 1. To assure welding quality, we used acetone to eliminate oil and rust on the steel plates. Efforts were made to prevent poor welding and dregs in the welding nugget. Then, twice welding mode was applied to prevent excessive heat on the steel plate at the welding point in a complete welding process and prevent splashes under pressure. The time interval between two welding processes was determined as $20 \mathrm{~ms}$, and the welding and holding times were set at $130 \mathrm{~ms}$ and $250 \mathrm{~ms}$, respectively. Initially, welding pressure was set at 4.100 $4.500 \mathrm{KN}$, and welding current was adjusted successively. After welding, tensile tests of samples were performed on a MTS810 universal testing machine to check the welding quality. Thereafter, welding current was adjusted according to tensile failures of samples.

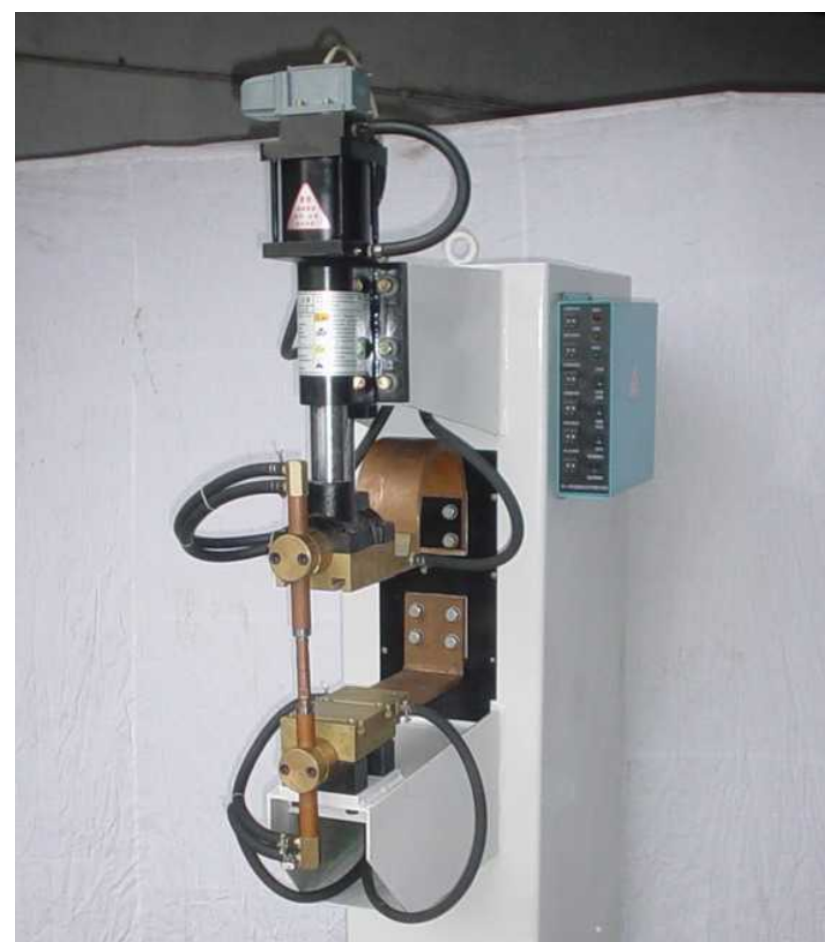

Fig.1 Resistance spot welding (RSW) equipment

A total of 10 samples were welded. Among them, two steel plates in \#1-\#6 samples were not melted completely at the welding point due to the relatively small welding current, so that the fusion zone (FZ) was relatively vulnerable when the samples were stretched. Finally, fractures occurred on the FZ interface (Fig. 2). Molten metal liquid splashes were produced in the \#7 sample under welding pressure due to excessive welding current. As a result, inadequate materials were found in the spot-welding zones and the heat affected zone (HAZ) was extremely thin. Thus, fractures occurred in the HAZ when the sample was stretched (Fig. 3). The welding parameters of \#8-\#10 samples were appropriate and the FZ was welded well, thereby forming enough strength. Therefore, fractures occurred at BM, which was close to HAZ when the samples were stretched (Fig. 4).

Fig. 4 shows that the FZ is not damaged and the welding quality is proven. Therefore, the RSW parameters are finally determined according to the current at welding of the \#8-\#10 samples (Table 1). 


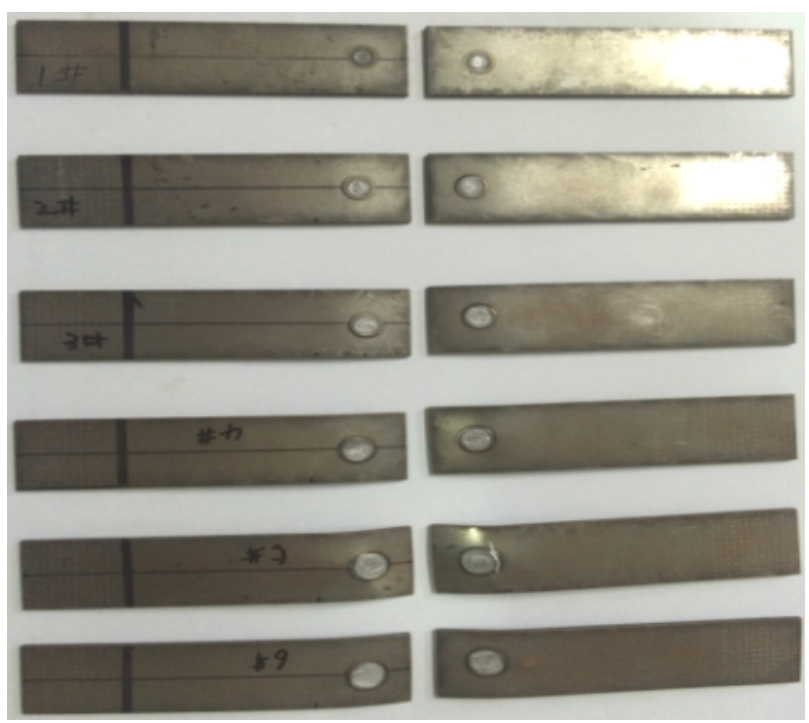

Fig. 2 Specimen 1-6

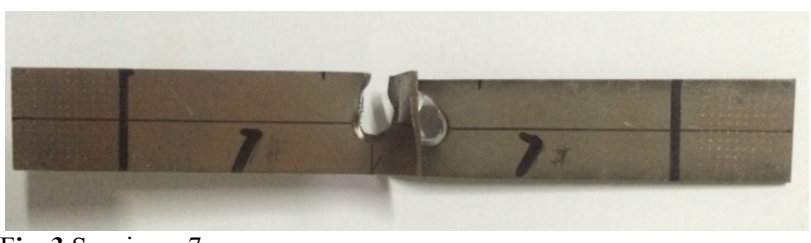

Fig. 3 Specimen 7

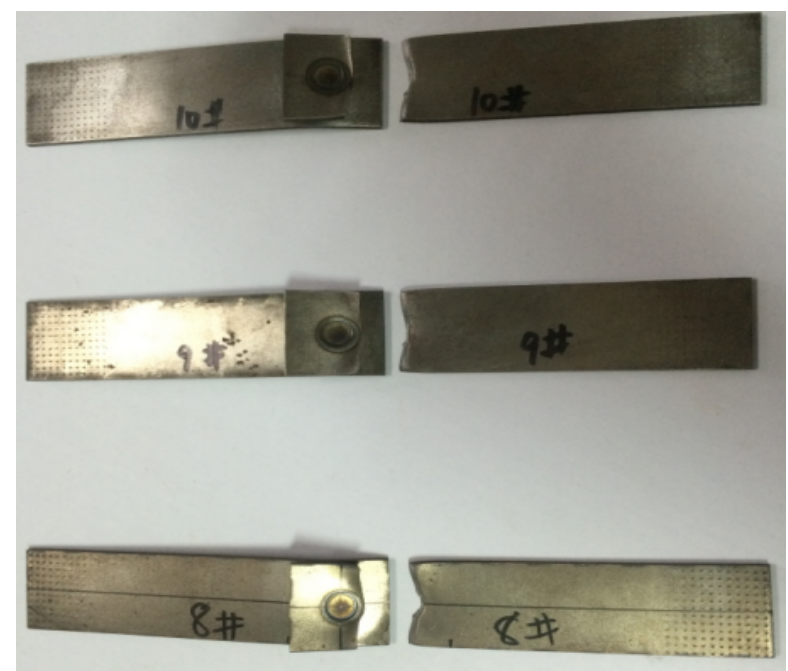

Fig. 4 Specimen 8-10

Table 1. RSW parameters

\begin{tabular}{l|l|l|l|l|l}
\hline Welder & $\begin{array}{l}\text { Weld } \\
\text { electrode }\end{array}$ & $\begin{array}{l}\text { Electrode } \\
\text { force } \\
\text { (kN) }\end{array}$ & $\begin{array}{l}\text { Welding } \\
\text { current } \\
\text { (A) }\end{array}$ & $\begin{array}{l}\text { Weld } \\
\text { time } \\
\text { (ms) }\end{array}$ & $\begin{array}{l}\text { Pressure } \\
\text { holding } \\
\text { time } \\
\text { (ms) }\end{array}$ \\
\hline $\begin{array}{l}\text { Mediumfrequency } \\
\text { direct current }\end{array}$ & Copper & 4.200 & 7200 & 130 & 250 \\
\hline
\end{tabular}

\subsection{Metallographic structural observation of welding} spots

Metallographic structure in the RSW zone of TRIP780 steel was identified to effectively understand the welding quality and internal structure of the RSW zone of TRIP780 steel. Formation process of FZ, fine division of HAZ, cause of welding defects, and distinguishing characteristics of martensite were further understood. First, metallographical experimental samples were selected. Squares $(20 \mathrm{~mm} \times 20$ $\mathrm{mm})$ were cut by centering at the welding point and then rectangles $(20 \mathrm{~mm} \times 10 \mathrm{~mm})$ were cut through the central profile of the spot-welding zone. The rectangles were used as samples in metallographic structural identification. For the convenience of grinding the FZ profile, samples were processed in a plastic package using a thermal inlaying machine (Fig. 5) to expose the FZ profile (Fig. 6). Then, profiles of FZ were grinded, including the coarse grinding first and then fine grinding. In the grinding process, abrasive papers from coarse to fine were applied and attention was paid to forces in the grinding process. Samples were grinded along the same direction to prevent crossing scratches.

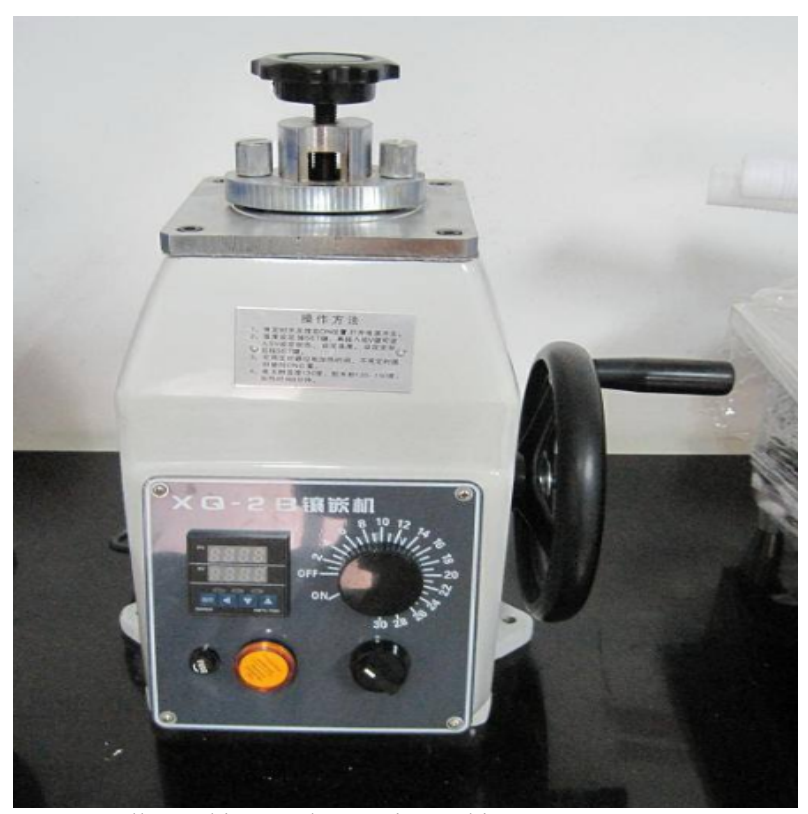

Fig. 5 Metallographic sample mosaic machine

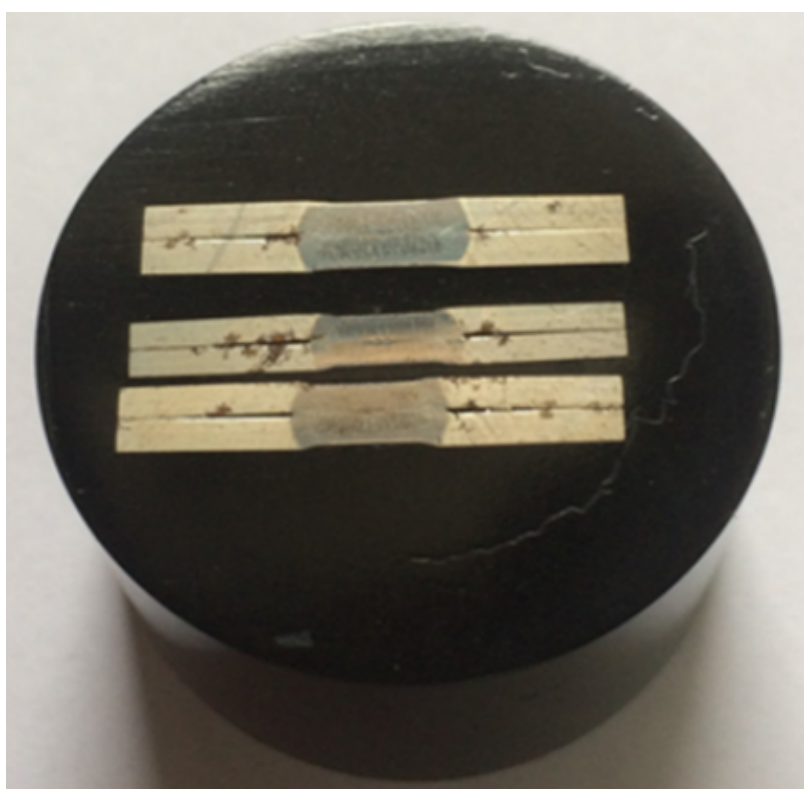

Fig. 6 (RSW) metallographic sample

Finally, samples were polished on a machine (Fig. 7). Wool and lint were used as polishing materials and polishing pastes from coarse to fine materials were selected successively. Moreover, samples were polished on two mutually perpendicular directions to prevent scratches. After polishing, samples were immersed in medicinal liquid for erosion. At the same time, metallographic structures of BM of 
TRIP780 steel were identified. Sample size was determined at $20 \mathrm{~mm} \times 20 \mathrm{~mm}$ (Fig. 8). Relevant experimental standards and conditions for metallographic structural identification are listed in Table 2.

In the fast-heating melting of RSW and subsequent cooling and solidification process, materials in the RSW zone were uneven due to the nonuniform temperature changes. As shown in Fig. 9, the structural composition of the RSW zone is a sandwich-like structure. The outer layer is the BM, the middle layer is the HAZ, and the inner layer is the FZ. Each layer has a completely different volume. Diameters of the FZ and HAZ were approximately $4.500 \mathrm{~mm}$ and $0.500 \mathrm{~mm}$, respectively. Moreover, the metallographic structures in each part were different. Thus, the RSW zone can be considered as a hybrid structure with small size and uneven materials. This structure increases the difficulties in conventional quasi-static and impact experiments on materials. Further explorations on effective constitutive equation under high strain rate and dynamic failure trajectory are necessary.

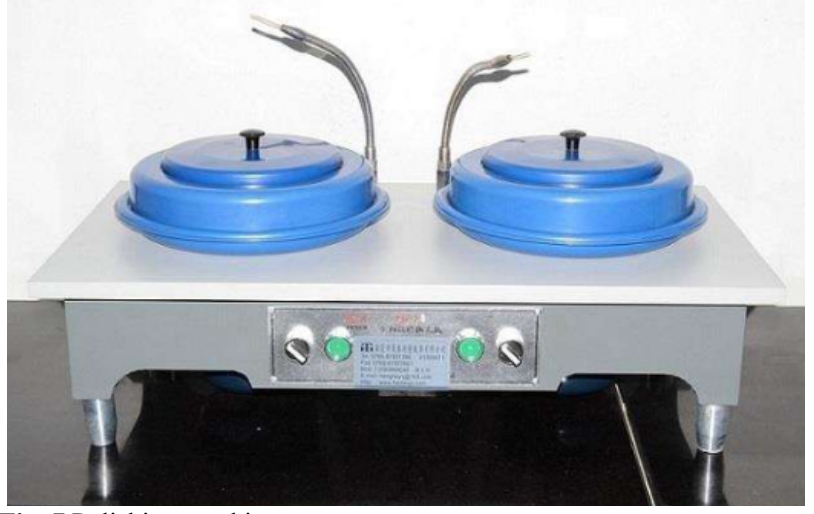

Fig. 7 Polishing machine

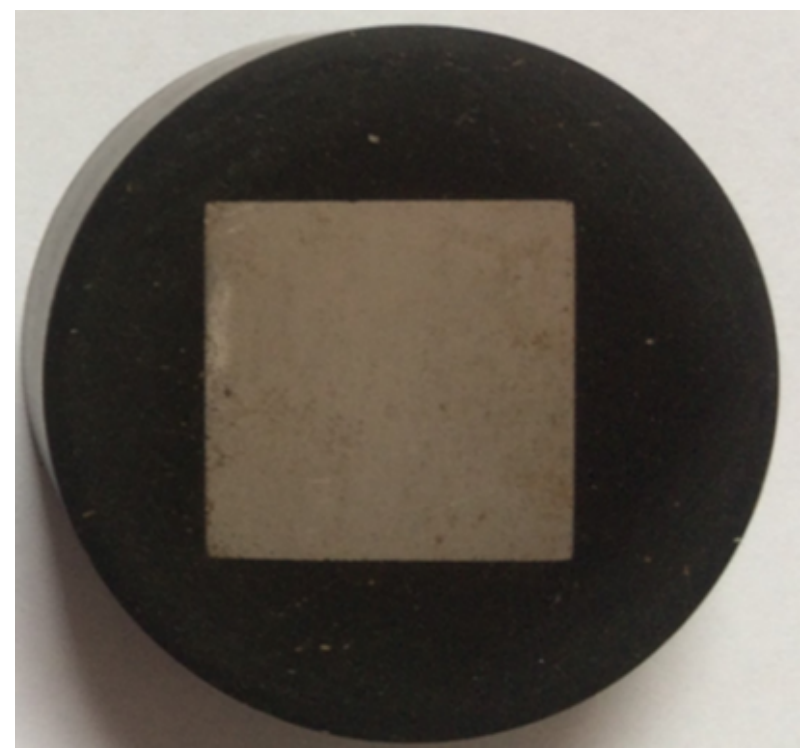

Fig. 8 Base metal(BM) metallographic sample

Table 2. Metallographic experiment standards and conditions

\begin{tabular}{l|l|l|l}
\hline Samples & $\begin{array}{l}\text { Experimental } \\
\text { standards }\end{array}$ & $\begin{array}{l}\text { Experimental } \\
\text { equipment }\end{array}$ & Etching agent \\
\hline $\begin{array}{l}\text { Resistance } \\
\text { spot weld } \\
\text { profile, BM } \\
\text { of TRIP780 } \\
\text { steel }\end{array}$ & $\begin{array}{l}\text { GB/T 13298- } \\
\text { Methods of }\end{array}$ & $\begin{array}{l}\text { Olympus GX71 } \\
\text { metallographic } \\
\text { microscope }\end{array}$ & $\begin{array}{l}4 \% \text { nital, } \\
\text { solution }(1 \% \\
\text { sodium } \\
\text { metabisulfite } \\
\text { aqueous solution } \\
=1: 1)\end{array}$ \\
\hline
\end{tabular}

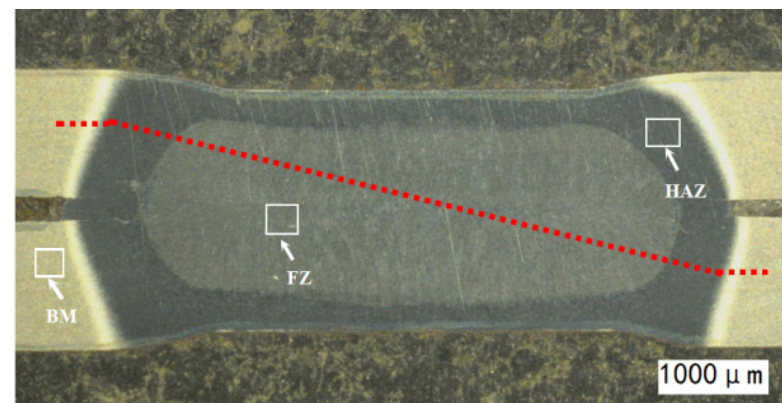

Fig. 9. The RSW cross-sectional micro-graph and dot position

\subsection{Design of micro-hardness test}

According to numerous experiments, the yield strength of metallic materials is related to the hardness value to a certain extent. The hardness of metallic materials refers to their ability to resist local deformation, especially plastic deformation and indentation under stress action. Hardness is included in a comprehensive index of mechanical properties that include elasticity, plasticity, strength, and roughness. The hardness test can be classified into various methods such as Brinell, Rockwell, and Vickers. The hardness value, which is obtained from an indentation hardness test, reflects the resistance of materials to plastic deformation. The resistance corresponds to the yield strength to a certain extent. A high yield strength indicates a stronger resistance to plastic deformation and high hardness value. Compared with the strength test, the hardness test is more convenient without causing damage to samples. Therefore, the correlation between hardness and yield strength is recognized by testing the hardness of metallic materials, which is conducive to obtaining their yield strength.

Vickers hardness (HV) test was performed on the RSW materials of TRIP780 steel. This method was proposed by Robert L. Smith and George E. Sandland at Vickers Ltd. in 1921. In the HV test, square-tapered diamonds with $136^{\circ}$ angle of opposite surfaces were pressed into the material surface by certain loads. The length of diagonal of indentation on the material surface was measured (Fig. 10). Then, the HV value of materials was calculated according to Eq. (1):

$$
H V=0.102 \times \frac{F}{A}
$$

where $\mathrm{F}$ is loads and $\mathrm{A}$ is surface area of indentation.

The HV test was divided into three levels according to the following loads:
1) in the range of $49.030-980.700 \mathrm{~N}$,
2 ) in the range of $1.961-<49.030 \mathrm{~N}$, and
3) at $<1.961 \mathrm{~N}$.

Micro HV test was applied to the RSW materials. A VMH-I04 micro-hardness tester was used as experimental apparatus (Fig. 11) and test standards used GB/T 4340.1-2009 Metallic Materials-Vickers Hardness Test-Part I: Test Method. In the experiment, test loads were $0.981 \mathrm{~N}(100 \mathrm{~g})$ in the micro HV test of the RSW samples, in which hardness was expressed as $308 \mathrm{HV} 0.1$.

Yield strength of BM of TRIP780 steel is approximately $500 \mathrm{MPa}$, whereas hardness of $\mathrm{BM}$ is about $260 \mathrm{MPa}$. With respect to the conversion relation between hardness and yield strength of metallic materials, Nielsen [27] estimated changes in the hardness of materials (known as yield stress) according to method of Kim Lau Nielsen [27]. Changes in hardness are measured according to Vickers micro-indentation hardness. 
An indentation load (100 g) was applied, and hardness was tested from point to point along a straight line that runs through the FZ. The tested hardness values were normalized by hardness of BM.

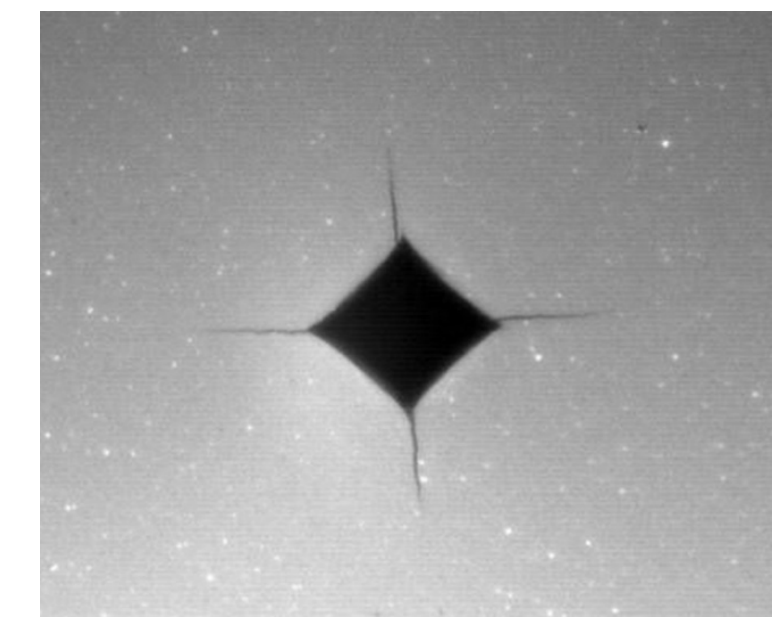

Fig.10 Hardness testing

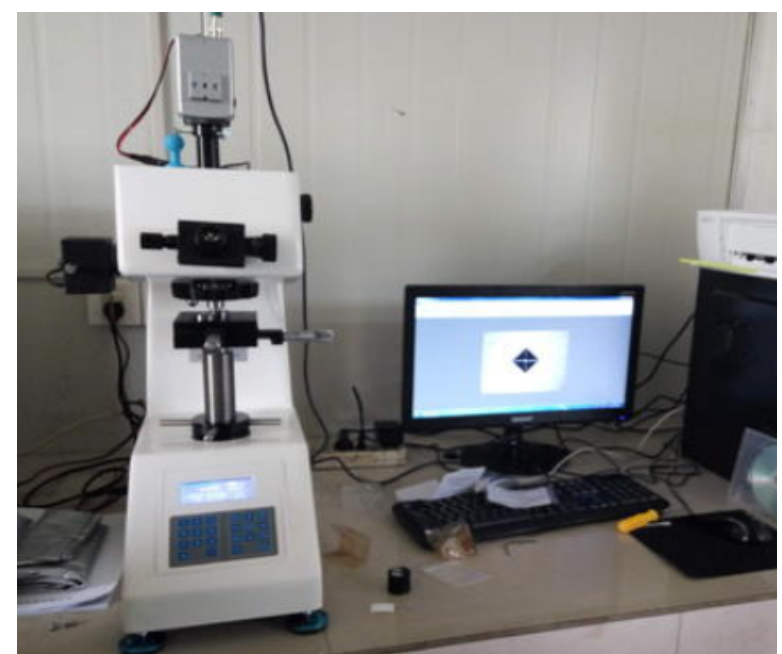

Fig. 11 Vickers micro-hardness tester

In other words, the yield strength of BM was used as the benchmark. According to the proportional relationship between the hardness of the RSW materials and that of BM,

$$
\lambda_{i}=\frac{H V_{i}}{H V_{B}}
$$

where $\lambda_{i}$ is the proportionality coefficient, $H V_{i}$ is the $\mathrm{HV}$ of the RSW materials, and $H V_{B}$ is the HV of BM.

Therefore, the yield strength of RSW materials can be deduced by the following formula:

$$
\sigma_{Y(R) i}=\lambda_{i} \sigma_{Y(B)}
$$

where $\sigma_{Y(R) i}$ is the yield strength of the RSW materials and $\sigma_{Y(B)}$ is the yield strength of BM.

\subsection{Design of dynamic compression experiment}

Cylinders with $5.00 \mathrm{~mm}$ diameter and $2.60 \mathrm{~mm}$ thickness were cut linearly in the FZ of the original samples. Uniaxial dynamic compressive test was conducted on the cylinders, in which SHPB devices were used (Fig. 12).

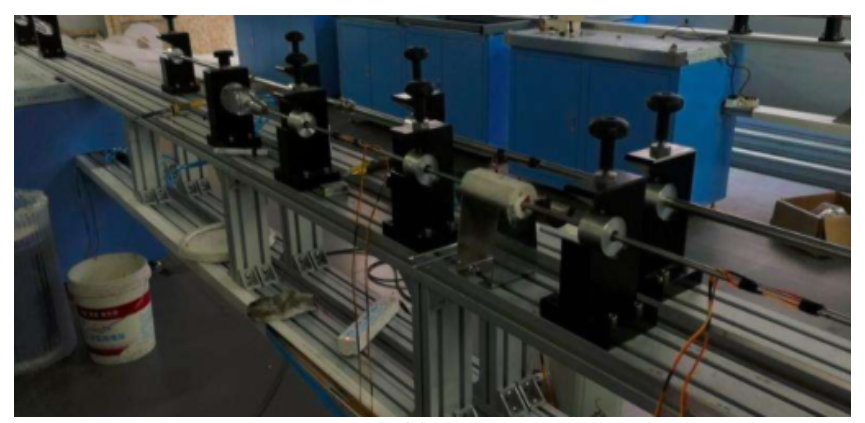

(a)

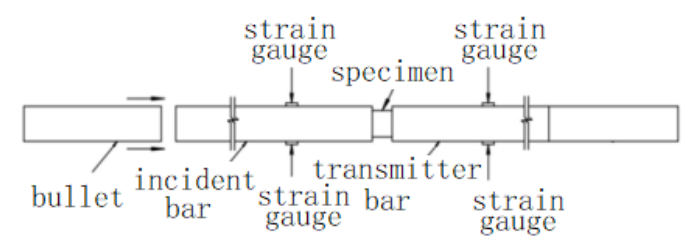

(b)

Fig. 12 Schematic diagram of Hopkinson pressure bar. (a)Equipment. (b)Schematic diagram

In the test, short specimens were clamped between the input and output bars. When the compressed air gun drives the impact bar (bullet) with a length of $L_{0}$ to impact on the target plate at the speed of $V_{0}$, the incidence bar is pulled and incidence stress pulse $\sigma_{I}(t)$ loads are generated. Under the effect of these incidence pulse loads, samples develop highspeed deformations. Meanwhile, the reflection stress pulse $\sigma_{R}(t)$ is spread to the incidence bar and the transmittance stress pulse $\sigma_{T}(t)$ is spread to the transmission bar. $\sigma_{R}(t)$ and $\sigma_{T}(t)$ reflect the dynamic behaviors of the specimen materials. Stress $\sigma(t)$, strain $\varepsilon(t)$, and strain rate $\dot{\varepsilon}(t)$ of the specimens were calculated by the typical second-wave method. Calculation formulas are shown in Eqs. (4), (5), and (6). In these equations, $\varepsilon_{T}(t)$ is the strain of the transmission bar and $\varepsilon_{R}(t)$ is the strain of the incidence bar.

$\sigma(t)=\frac{A_{0}}{A_{s}} E_{0} \varepsilon_{T}(t)$

$\varepsilon(t)=-\frac{2 C_{0}}{L_{s}} \int_{0}^{t} \varepsilon_{R}(t) d t$

$\dot{\varepsilon}(t)=-\frac{2 C_{0}}{L_{s}} \varepsilon_{R}(t)$

$E_{0}$ and $C_{0}$ are the elasticity modulus of the bars and elastic wave speed on bars. $A_{0}$ and $A_{s}$ are cross-sectional areas of bars and specimens. $L_{s}$ is the effective length of specimens. 
Signal distortion may occur in the SHPB test because the diameter of the welding joint samples is smaller and hardness is higher than those of the compression bar. Therefore, a conic tungsten carbide cushion block is added between the welding joint specimen and the bar (Fig. 13) to improve the reflection and transmission of stress waves between them. The waveform comparison of typical oscillators with and without cushion blocks is shown in Fig. 14, where the waveform with a cushion block is improved significantly.

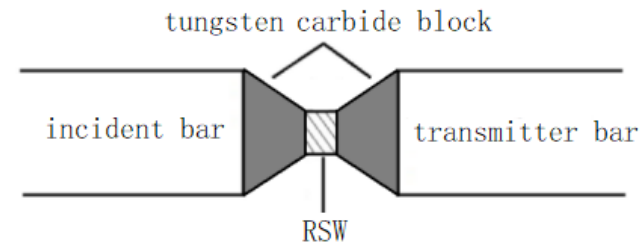

Fig. 13 Tungsten Carbide block

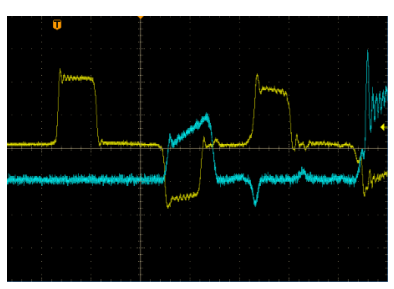

(a)

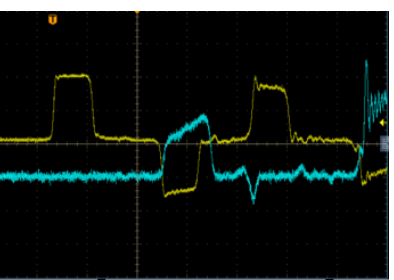

(b)
Fig. 14 Typical oscilloscope record of the modified SHPB test. (a) No blocks. (b) Increased blocks

\section{Result analysis and discussion}

According to experimental results of the metallographic structural identification in the welding zone, the low-power morphology of the spot-welding zone is shown in Fig. 9. Profiles of different parts of the spot-welding zone, which are FZ, HAZ, and BM, from the inner to the outer part can be observed in Fig. 9. As the RSW zone is extremely small and the diameter is only several millimeters, the mechanical properties of BM, HAZ, and FZ are different. The spotwelding zone is a hybrid structure. For such RSW materials, the traditional quasi-static and dynamic tensile (compressive) tests cannot be conducted.

Martensite is the metallographic structure in the molten zone of RSW (Fig. 15). Coarse lath-shaped martensites are found close to the FZ center, which are in radioactive distribution along the center. This distribution pattern is due to outside-in crystallization upon temperature reduction when two steel plate layers are molten at welding point.

Loose defects are observed in the center of the spotwelding zone (Fig. 16). This condition can be interpreted as follows. Plate materials in the welding zone are cooled and crystalized from outside to inside, and the martensite density formed by crystals is higher than the original ferrite density of the plate materials. As a result, the volume in the center of the molten zone is inadequate after crystallization and loose defects are formed. These defects can cause important impacts on the strength of RSW and stability of the RSW structure.

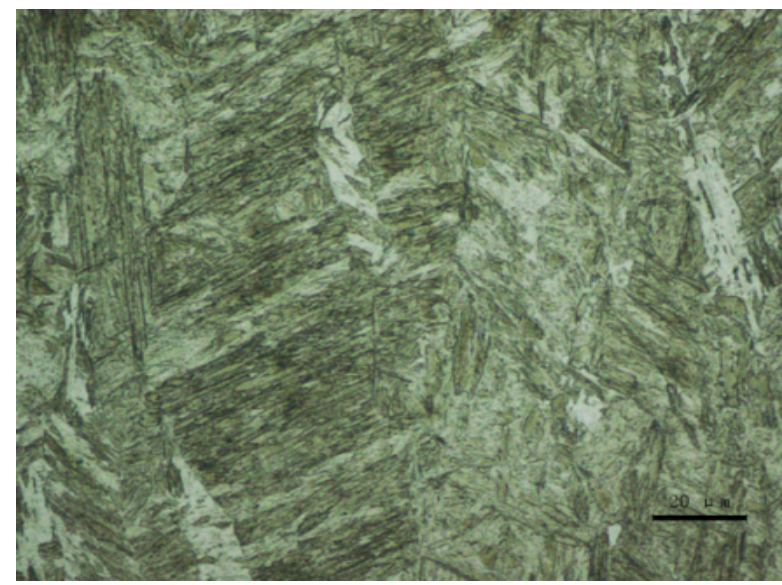

Fig. 15 The micrograph in the FZ. $(500 \times)$

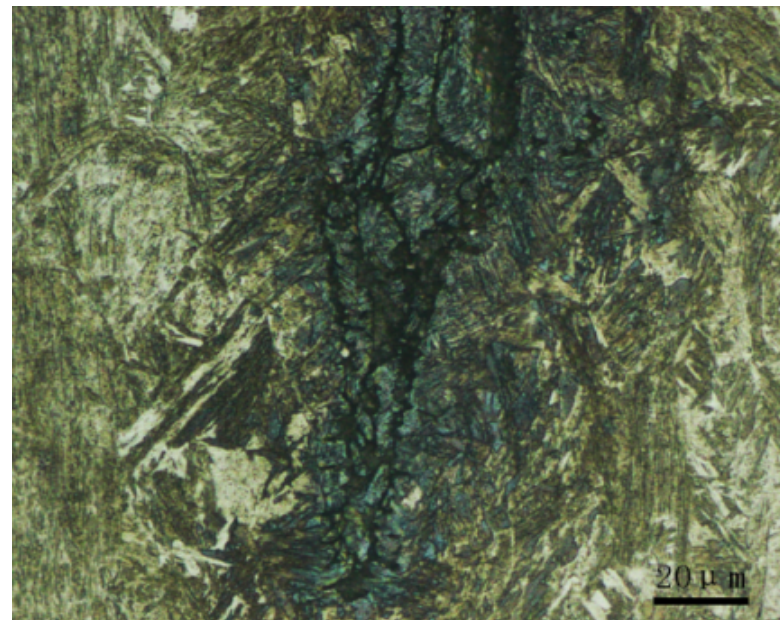

Fig. 16 The micro-cracks, shrinkage void and pore in the center of the RSW. $(500 \times)$

The upper and lower edge structures of FZ are shown in Fig. 17. Clearly, significant differences of morphologies occur among different parts. However, transition sections are found in FZ, HAZ, and BM, which reflect the formation of different crystalline structures in the spot-welding zones under the influence of temperature in the welding process. Martensite crystals diminish gradually from FZ to HAZ. Partial phase transformation zones exist between HAZ and $\mathrm{BM}$. In this region, the metallographic structure is divided into partial martensite and partial ferrite. The metallographic structure in the partial phase transformation zone of martensite + residual ferrite is shown in Fig. 18.

The HV test was performed on the RSW materials of TRIP780 steel. To disclose the HV values of BM, HAZ, and FZ on the RSW material samples, points were set on the left $\mathrm{BM}$ and $\mathrm{HAZ}$, center FZ, and right $\mathrm{HAZ}$ and BM successively along a biased line that runs through the FZ center. Specifically, points were set horizontally along the center line of BM of the steel plate $(1 \mathrm{~mm})$, then turning to the $\mathrm{FZ}$ center from the outer edge of $\mathrm{HAZ}$, running through the FZ center and to the horizontal direction of the outer edge of the opposite HAZ $(1 \mathrm{~mm})$. The interval between the two points was $0.200 \mathrm{~mm}$. Distribution of the testing points is shown in the dotted line in Fig. 9. This study set five points in the right and right $\mathrm{BM}$ zones, respectively; 4 points in the right and right HAZ zones, respectively; and 26 points in the center FZ zone. Therefore, a total of 44 hardness test points in the RSW zone were set. 


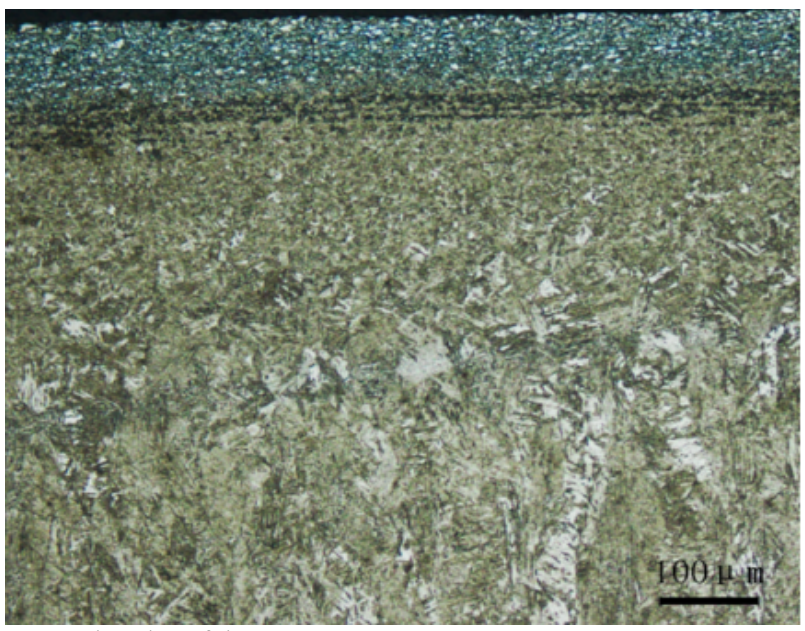

Fig.17 The edge of the RSW.

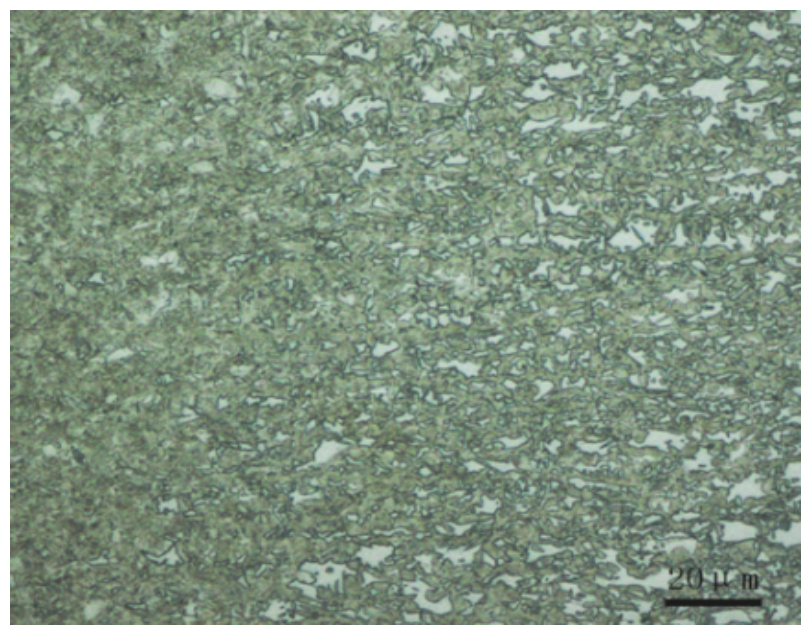

Fig.18 The micro-graph near the boundary between HAZ and BM.

Specific HV test results are listed in Table 3. For a clear display of the HV hardness values of different parts of the RSW material samples, experimental results and length of RSW material samples were placed in the same coordinate system and a variation curve of the hardness with length was drawn (Fig. 19).

Table 3. The results of hardness experiment

\begin{tabular}{c|c|c|c|c|c|c}
\hline Zone & \multicolumn{5}{|c}{ Vickers hardness value } \\
\hline $\begin{array}{c}\text { left } \\
\text { base metal }\end{array}$ & 263 & 270 & 282 & 254 & 269 & $/$ \\
$\begin{array}{c}\text { Left hot- } \\
\text { affected zone }\end{array}$ & 351 & 482 & 495 & 491 & $/$ & $/$ \\
& 487 & 516 & 501 & 514 & 500 & $/$ \\
& 513 & 504 & 517 & 494 & 500 & $/$ \\
Weld & 524 & 528 & 530 & 512 & 512 & 515 \\
core & 504 & 509 & 504 & 509 & 487 & $/$ \\
& 491 & 491 & 478 & 492 & 492 & $/$ \\
right hot- & 503 & 477 & 530 & 356 & $/$ & $/$ \\
affected zone & & & & & & \\
right & 262 & 263 & 263 & 265 & 258 & $/$ \\
base metal & 262 &
\end{tabular}

In the welding process, bainites in BM are transformed into austenites. With the continuous increase of temperature, ferrites in BM can also be transformed into austenites. Under this circumstance, plastic deformation is developed in the welding zone under spot-welding pressure. With the reduction of temperature, structures are recrystallized and martensitic structures are obtained after cooling. Fig. 19 shows that the hardness values of FZ and HAZ are relatively high, whereas that of BM is relatively low. The main reason is that FZ and HAZ are mainly composed of martensites, while BM is mainly composed of ferrites. The hardness values of martensites are higher than those of ferrites. The hardness values of FZ are different from those of HAZ because HAZ components include some residual ferrites relative to the components of $\mathrm{FZ}$, thereby resulting in lower hardness of HAZ than that of FZ. In Fig. 19, point S shows the softening point of hardness, which is less than the hardness of wood. The micro-hardness decreases as the steel plates receive fast thermal circulation at welding.

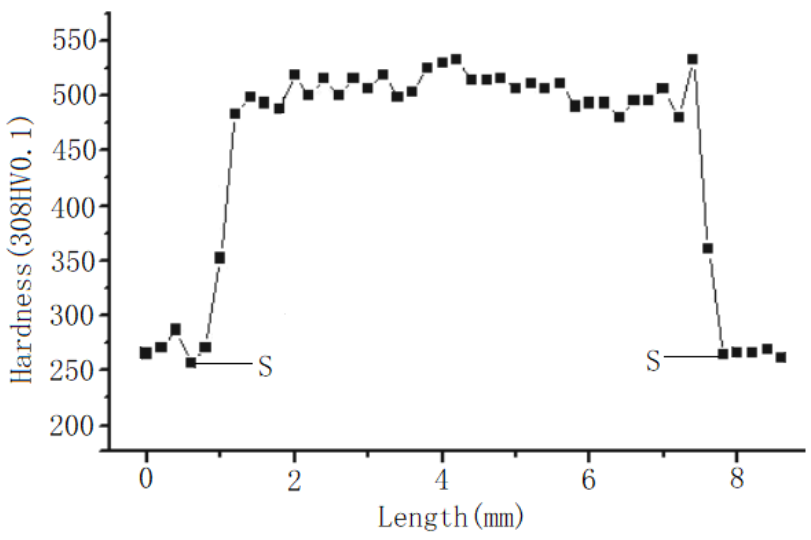

Fig. 19 Hardness-length curve

Roth [26] decoupled the strain hardening effect, strain rate hardening effect, and temperature softening effect of materials with reference to the Johnson-Cook constitutive model, thereby obtaining the following dynamic constitutive equation:

$$
\begin{aligned}
& \sigma_{e}^{B M}\left(\varepsilon_{p}, \dot{\varepsilon}_{p}, T\right) \\
& =\left[\alpha A_{*}\left(\varepsilon_{p}+\varepsilon_{0}\right)^{n}+(1-\alpha)\left(k_{0}+Q\left(1-e^{-\beta \varepsilon_{p}}\right)\right)\right] . \\
& {\left[1+C_{*} \ln \left(\frac{\dot{\varepsilon}_{p}}{\dot{\varepsilon}_{0}}\right)\right]\left[1-\left(\frac{\Delta T}{T_{m}-T_{r}}\right)^{m}\right]}
\end{aligned}
$$

where $B M$ refers to base material, $\varepsilon_{p}$ denotes equivalent plastic strain; $\dot{\varepsilon}_{p}$ is plastic strain rate; $\Delta T$ denotes temperature rise caused by plastic powers; $\alpha$ is the linear combination coefficient; and $k_{0}, Q$, and $\beta$ are constants.

The expression of $\Delta T$ is

$\Delta T=\frac{\eta_{k}}{C_{p} \rho} \int \bar{\sigma} d \varepsilon_{p}$

where $\eta_{k}$ is Taylor-Quinney coefficient, $\rho$ is mass density, and $C_{p}$ is hot melting.

Model parameters of TRIP780 steel used in numerical simulation of a typical experiment are listed in Table 4.

Table 4. The modified Johnson-Cook model parameters for TRIP780 steel used in simulation 


\begin{tabular}{c|c|c|c|c|c}
\hline $\begin{array}{c}A_{*} \\
(\mathrm{MPa})\end{array}$ & $\varepsilon_{0}$ & $n$ & $C_{*}$ & $\dot{\varepsilon}_{0}$ & $m$ \\
\hline 1526.5 & 0.00519 & 0.242 & 0.00557 & 0.00321 & 1.025 \\
$T_{r}$ & $T_{m}$ & $\begin{array}{c}E \\
(\mathrm{KPa})\end{array}$ & $v$ & $C_{p}$ & $\begin{array}{c}\rho \\
(\mathrm{K})\end{array}$ \\
293 & 1806.7 & 185 & 0.33 & 420 & 7850 \\
\hline
\end{tabular}

As the material properties of the welding zone are significantly different from BM in the welding process, we hypothesized that only changes of yield stress in the welding zone are considered in the numerical model, and other mechanical properties and failure parameters are constant in the specimens, as mentioned by Nielsen [27]. It is hypothesized that a linear correlation exists between microhardness and yield stress. Therefore, hardness in the RSW zone is attributed to the hardness of BM. On this basis, the dynamic constitutive equation of the RSW zone of TRIP780 steel is obtained as follows:

$$
\begin{aligned}
& \sigma_{e}^{R S W}\left(\varepsilon_{p}, \dot{\varepsilon}_{p}, T\right) \\
& =\lambda_{i} \sigma_{e}^{B M}\left(\varepsilon_{p}, \dot{\varepsilon}_{p}, T\right) \\
& =\lambda_{i}\left[\alpha A\left(\varepsilon_{p}+\varepsilon_{0}\right)^{n}+(1-\alpha)\left(k_{0}+Q\left(1-e^{-\beta \varepsilon_{p}}\right)\right)\right] \\
& \cdot\left[1+C \ln \left(\frac{\dot{\varepsilon}_{p}}{\dot{\varepsilon}_{0}}\right)\right]\left[1-\left(\frac{\Delta T}{T_{m}-T_{r}}\right)^{m}\right]
\end{aligned}
$$

where $R S W$ represents RSW materials.

Dynamic uniaxial compression stress - strain curve of the welding joint specimens under different strain rates is shown in Fig. 7. The dynamic uniaxial compression test results of welding joint specimens were analyzed by using the previously obtained dynamic constitutive equation of RSW materials of TRIP780 steel (Eq. (9)). Test results were compared with the curve that was obtained from the experiment (Fig. 20). According to comparison results, the hardness of the RSW material is attributed to the hardness of $\mathrm{BM}$ based on the hypothesis of linear correlation between micro-hardness and yield stress. The dynamic constitutive equation for the RSW material of TRIP780 steel is applicable to the numerical analysis of the dynamic mechanical behavior of the RSW materials. Moreover, strain rate dependence of dynamic compression behaviors of martensites is observed in the molten zone of the RSW material.

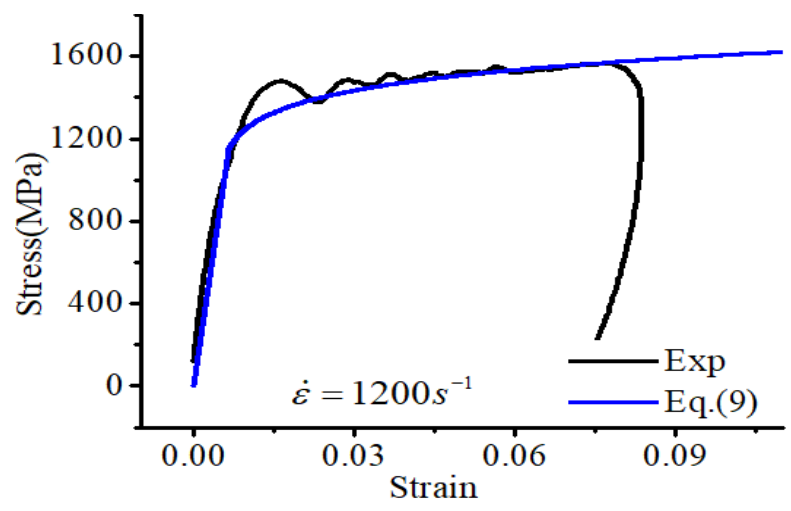

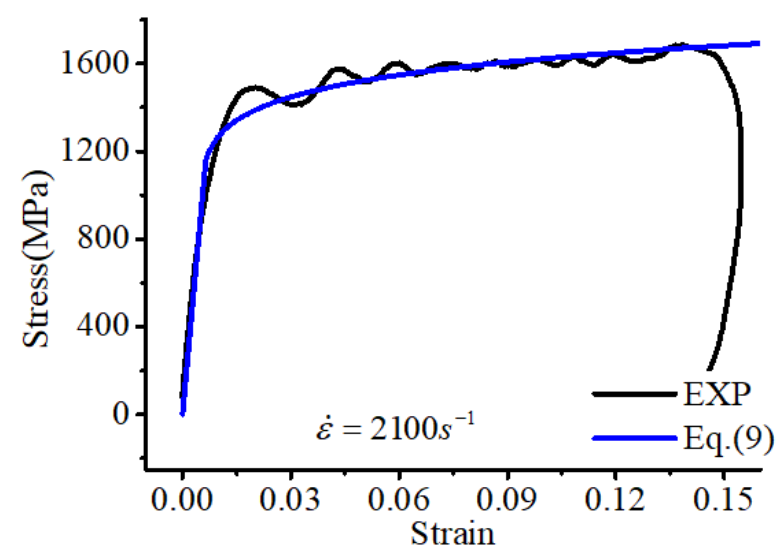
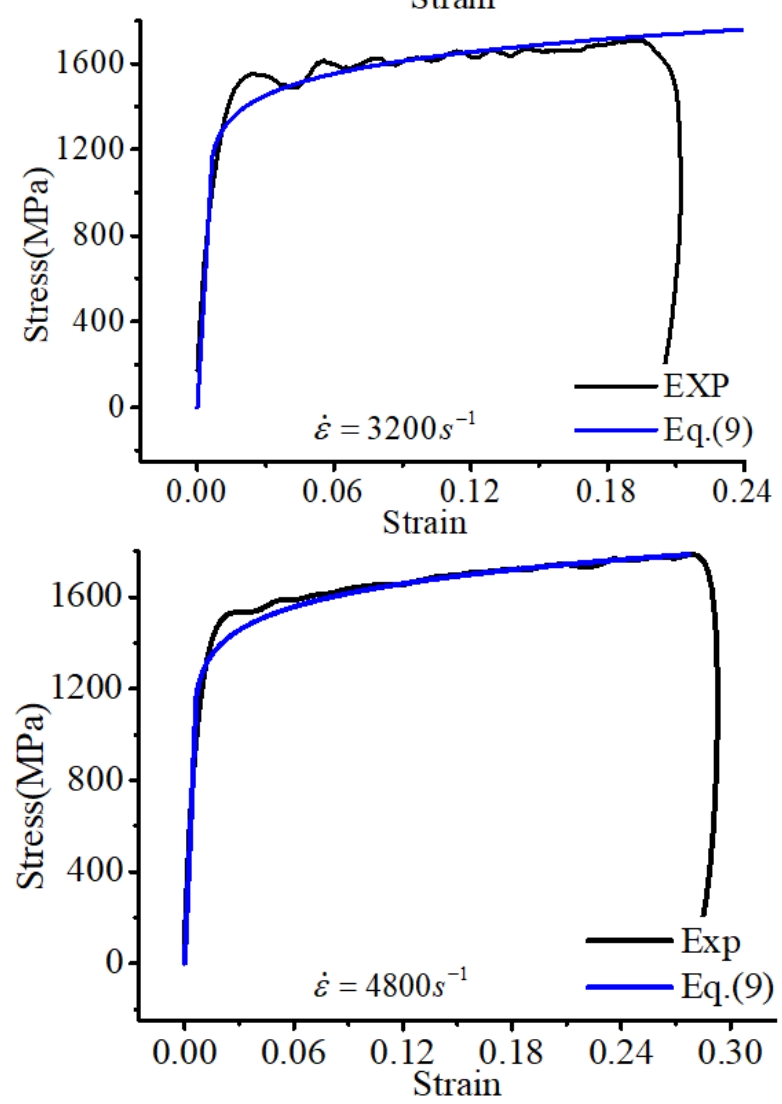

Fig. 20 Comparison between experimental results and numerical simulation

\section{Conclusions}

To obtain the dynamic constitutive equation of the RSW material of TRIP780 steel, the relations between the constitutive equations of BM and RSW materials are searched from the connection between the micro-hardness and yield strength of the materials. On this basis, a micro-hardness experiment on the RSW material was designed and implemented, and its hardness distribution was analyzed. At the same time, a dynamic compression experiment of the RSW material of TRIP780 steel was implemented. Numerical analysis of experimental results is performed. The following major conclusions can be drawn:

1) Local martensite content and martensite tempering directly influence the compression strength of RSW materials.

2) In the thermal cyclic welding process, the instantaneous peak temperature, which was higher than the critical temperature, triggers significant changes in the material hardness and strength of FZ and HAZ. 
3) An effective dynamic constitutive equation of the RSW material was obtained and numerical simulation of the experimental results was conducted.

4) The dynamic compression behavior of martensite in FZ was characterized by strain rate dependence.

By combining the experimental study and numerical calculation, this study proposed a dynamic constitutive equation for the RSW material of TRIP780 steel. Setting this equation was a simple and direct process, and is important in studying the mechanical behaviors of the RSW material under high strain rate. In the future, dynamic compression and tensile tests of the RSW material can be designed to further explore the mechanical behaviors of this material.

This is an Open Access article distributed under the terms of the Creative Commons Attribution License

\section{References}

1. Galindo-Nava, E. I., Rivera-Diaz-del-Castillo, P. E. J., "Understanding martensite and twin formation in austenitic steels: A model describing TRIP and TWIP effects". Acta Materialia, 128(1), 2017, pp.120-134.

2. Zackay, V. F., Parker, E. R., Fahr, D., "The Enhancement of Ductility on High-Strength Steel". Transactions of Applied Structures Mechanics, 60(2), 1967, pp.252-258.

3. Min, J. Y., Louis G. H. J., Zhang, L., Lin, J. P., John E. C., Sun, L., "Elevated-temperature mechanical stability and transformation behavior of retained austenite in a quenching and partitioning steel". Materials Science and Engineering: A, 673(1), 2016, pp.423-429.

4. Martinez, A., Miguel, V., Coello, J., Manjabacas, M. C., "Determining stress distribution by tension and by compression applied to steel: Special analysis for TRIP steel sheets". Materials and Design, 125(3), 2017, pp.11-25.

5. Christodoulou, P. I., Kermanidis, A. T., Haidemenopoulos,G. N., Krizan, D., Polychronopoulou, K., "Effect of retained austenite stability on cyclic deformation behavior of low-alloy transformationinduced plasticity steels". Fatigue and Fracture of Engineering Materials and Structures, 42(10), 2019, pp.1085-1099.

6. Seyed, M. K. H., Abbass, Z. H., Steve, Y., "Microstructure Development and Mechanical Properties of Low-Silicon-Content TRIP-Assisted Steels after Coiling Process". Steel Research International, 87(2), 2016, pp.146-156.

7. Andrey, B., Rustam, K., Vladimir, T., "Microstructure and Mechanical Properties of $18 \% \mathrm{Mn}$ TWIP/TRIP Steels Processed by Warm or Hot Rolling”. Steel Research International, 88(2), 2017, pp.171-175.

8. Haidemenopoulos, G. N., Katsamas, A. I., Nikolaos, A., "Stability and Constitutive Modelling in Multiphase TRIP Steels". Steel Research International, 77(9), 2016, pp.720-726.

9. Huang, R. Y., Xie, Y. M., Tang, W., Zhang, F., Pan, B. B., "Experiment and simulation on twist springback for the double $\mathrm{C}$ rail of TRIP780 high strength steel based on mixed hardening model". Chinese Journal of Engineering Design, 24(6), 2017, pp.668-674.

10. Han, X. H., Wang, C. L., Li, Y.Y., Liu, G., "Effects of quenching and partitioning process on mechanical properties of TRIP780 steel". Journal of Iron and Steel Research International, 26(9), 2019, pp.991-999.

11. Han, X. H., Zhang, H. Z., Li, Y.Y., Tang, J. J., Wang, C. L., Chen, J., "Investigation of the Hot Stamping Process for TRIP Steel with High Strength and High Ductility". Journal of Materials Engineering and Performance, 28(10), 2019, pp.6125-6134.

12. Zhou, C., Zhang, W. T., Zhang, S. J., Deng, J. J., Xia, Q. X., "Effect of Strain Path Change on Formability of TRIP Steels". Materials Science Forum, 920(1), 2018, pp.223-229.

13. Zhu, J., Huang, S. Y., Liu, W., Hu, J. H., Zou, X. F., "Forming limit prediction of sheet metals by M-K model with various yield functions". International Journal of Microstructure and Materials Properties, 12(5), 2017, pp.348-362.
14. Yu, H. Y., Chen, S. J., "A mixed hardening model combined with the transformation-induced plasticity effect". Journal of Manufacturing Processes, 28(2), 2017, pp.390-398.

15. Chen, K., Liu, X., Ni, J., "Keyhole refilled friction stir spot welding of aluminum alloy to advanced high strength steel". Journal of Materials Processing Technology, 249(5), 2017, pp.452-462.

16. Dunand, M., Mohr, D., "Predicting the rate-dependent loading paths to fracture in advanced high strength steels using an extended mechanical threshold model". International Journal of Impact Engineering, 108(2), 2017, pp.272-285.

17. Mauduit, C., Kubler, R., Barrallier, L., Berveiller, S., Puydt, Q., Monin, M., Weber, B., "Analysis of Residual Stress Relaxation Under Mechanical Cyclic Loading of Shot-Peened TRIP780 Steel”. In: 10th International Conference on Residual Stre, Sydney, Australia: ICRS, 2017, pp.85-90.

18. Choi, S. G., Hwang, I., Kang, M. J., Hyun, S., "Optimization of Welding Parameters in Resistance Spot Welding of $980 \mathrm{MPa}$ Grade GA Steel Sheet using Multi-Response Surface Methodology". Journal of Welding and Joining, 36(4), 2018, pp.63-69.

19. Podany, P., Reardon, C., Koukolikova, M., Prochazka, R., Franc, A., "Microstructure, Mechanical Properties and Welding of Low Carbon, Medium Manganese TWIP/TRIP Steel”. Metals, 8(4), 2018, pp.263.

20. Vanova, P., Sojka, J., Konecna, K., Radkovska, T., "Comparison of Behaviour of Different Variants of Hydrogenated TRIP Steels at Slow Strain Rate Tests". Key Engineering Materials, 810(4), 2019, pp.70-75.

21. Onar, V., Aslanlar, S., "Welding Time Effect of Welding Joints in Micro Alloyed and TRIP 800 Steels in Resistance Spot Welding". Acta Physica Polonica, 131(3), 2017, pp.389-392.

22. Hajiannia, I., Shamanian, M., Atapour, M., Ghassemali, E., Ashiri, R., "A microstructure evaluation of different areas of resistance spot welding on ultra-high strength TRIP1100 steel". Cogent Engineering, 5(1), 2018, pp.1-13.

23. Mostafapour, A., Ebrahimpour, A., Saeid, T., "Finite element investigation on the effect of FSSW parameters on the size of welding subdivided zones in TRIP steels". International Journal of Advanced Manufacturing, 88(1), 2017, pp.277-289.

24. Gladys, P. Medina., Hugo, L., Argelia, M. P., "Effect of grain recrystallization on stir zone and mechanical property behavior of TRIP 780 steel". Journal of Iron and Steel Research International, 27(8), 2020, pp.188-196.

25. Xie, R. J., Li, C. Z., Zheng, G., Chen, F. R., "Study on microstructure and mechanical properties of spot welded joints of TRIP980 high strength steel". Transactions of the China Welding Institution, 40(1), 2019, pp.119-123,136.

26. Roth, C. C., Mohr, D., "Effect of strain rate on ductile fracture initiation in advanced high strength sheet". International Journal of Plasticity, 56(4), 2014, pp.19-44.

27. Nielsen, K. L., "3D modelling of plug failure in resistance spot welded shear-lab specimens (DP600-steel)". International Journal of Fracture, 153(2), 2008, pp.125-139. 